\title{
Induced Hypoxia in Rat Pulp and Periapex Demonstrated by ${ }^{3} \mathrm{H}$-Misonidazole Retention
}

\author{
K.R. Baumgardner ${ }^{1 *}$, R.E. Walton ${ }^{2}$, J.W. Osborne ${ }^{3}$, and J.L. Born ${ }^{4}$ \\ ${ }^{1}$ Department of Cariology, Restorative Sciences, and Endodontics, School of Dentistry, Ann Arbor, Michigan 48109-1078; ${ }^{2}$ Department of \\ Endodontics, College of Dentistry, University of lowa, Iowa City, Iowa 52242; ${ }^{3}$ Radiation Research Laboratory, 14 Medical Laboratory, \\ University of lowa, lowa City, Iowa 52242; and ${ }^{4}$ College of Pharmacy, University of New Mexico, Albuquerque, New Mexico 87131; ${ }^{*}$ to \\ whom correspondence and reprint requests should be addressed
}

\begin{abstract}
Cellular hypoxia may be a useful indication of tissue distress in the dental pulp that could be used to investigate the early stages of pulpal responses. Tritiated misonidazole $\left({ }^{3} \mathrm{H}-\mathrm{MISO}\right)$ is a marker which preferentially labels cells with decreased oxygen tension (hypoxia). The experiments reported here were carried out to determine whether this agent could distinguish between hypoxic and normoxic pulp and periapical tissues. Rats were injected intra-peritoneally with either ${ }^{3} \mathrm{H}-\mathrm{MISO}$, unlabeled MISO, or saline, then divided into normoxic, hypoxic, and control groups. Normoxic animals were maintained at ambient pressure. We induced hypoxia by maintaining animals in a hypobaric chamber at $0.5 \mathrm{~atm}$ for $24 \mathrm{hrs} .{ }^{3} \mathrm{H}-\mathrm{MISO}$ retention was assessed by quantitative analysis of tissue autoradiographs. ${ }^{3} \mathrm{H}$-MISO retention rates in normoxic animals showed little variation except for increased retention in mature ameloblasts and immature odontoblasts in the continually erupting incisor. In both incisor and molar pulps, hypobaric hypoxia significantly increased ${ }^{3} \mathrm{H}$-MISO retention when compared with normoxic controls. Hypobaric hypoxia also resulted in intense ${ }^{3} \mathrm{H}$-MISO retention in cellular cementum, periodontal ligament, osteocytes, and, occasionally, in molar pulp horn odontoblasts. This study demonstrated that, with standard autoradiographic techniques, ${ }^{3} \mathrm{H}-\mathrm{MISO}$ can label induced hypoxic disturbances in the pulp and surrounding periodontium.
\end{abstract}

Key words: hypoxia, misonidazole, dental pulp, odontoblasts, ameloblasts, male Sprague-Dawley rats.

Received November 6, 1995; Accepted June 6, 1996

\section{Introduction}

The dental pulp, when subjected to inflammatory stress, cannot swell, and its interstitial fluid pressure rises (Van Hassel, 1971). One consequence of increased pulpal pressure may be cellular hypoxia. Hypoxia is defined as a decrease in the normal oxygen tension $\left(\mathrm{pO}_{2}\right)$ of the cell. Hypoxia may be the first indication in the pulp that cells are being metabolically challenged (Biesterfeld et al., 1979).

Misonidazole, 1-(2-hydroxy-3-methoxypropyl)-2-nitro$1 \mathrm{H}$-imidazole (MISO), has been used in experimental cancer therapy because of its ability to sensitize hypoxic tissue to the free radical effects of ionizing radiation and its ability to bind covalently, selectively, to hypoxic cells. Selective binding of MISO to hypoxic cells has been demonstrated in cell culture (Chapman et al., 1981; Raleigh et al., 1985), in animals (Chapman et al., 1981), and in humans (Urtasun et al., 1986).

For ${ }^{3} \mathrm{H}-\mathrm{MISO}$ to bind covalently to a cell, the nitro group must undergo a four-electron reduction to produce a hydroxylamine (Varghese and Whitmore, 1980; Franko, 1986). The bioactivated hydroxylamine covalently binds only in the cell where the reduction occurs (Varghese and Whitmore, 1980; Van Os-Corby et al., 1987). Thus, a radioactive label attached to MISO will be retained in the cell where reduction takes place (Raleigh et al., 1985; Franko et al., 1989).

MISO binds only slightly to normoxic sites due to futile RED/OX cycling, since oxygen limits the amount of reactive MISO derivative produced (Franko, 1986). Cellular hypoxia favors substantial reduction of MISO to hydroxylamine that subsequently binds within the cell (Varghese et al., 1976).

A method for labeling hypoxic cells with tritiated misonidazole ( $\left.{ }^{3} \mathrm{H}-\mathrm{MISO}\right)$ was described by Chapman et al. (1981). This technique was later used to demonstrate the presence of hypoxic cells in tumors (Urtasun $e t$ al., 1986) and selected normal tissues (Cobb et al., 1989a).

A possible complication to the use of ${ }^{3} \mathrm{H}$-MISO as a hypoxic cell marker was the report by Cobb et al. (1989a) that certain tissues retained more ${ }^{3} \mathrm{H}$-MISO than others, even under putative normoxic conditions. Either localized hypoxia was normal and common in sites where labeling occurred, or some undefined chemical reduction mechanism permitted deposition of the tritium label under 
normoxic conditions. Therefore, when ${ }^{3} \mathrm{H}-\mathrm{MISO}$ is used as a hypoxic cell marker, the normoxic retention rate must first be characterized, and increased retention due to hypoxia must be readily detectable.

Increased hypoxic retention of bioreductive drugs has been tested in vivo by a variety of methods to induce hypoxia, including blood vessel clamping (Bremner et al., 1990), administration of flavone acetic acid (Sun and Brown, 1989), 5-hydroxytryptamine (Chaplin, 1986), and hydralazine (Bremner et al., 1990). These methods cause hypoxia by reducing blood flow, which has the disadvantage of decreasing drug delivery to the tissue. In contrast, a hypobaric chamber causes tissue hypoxia by physical reduction of the partial pressure of oxygen (McAleer et al., 1992). Changes in blood flow secondary to hypoxia cannot be completely discounted, but MacManus et al. (1989) observed increased MISO binding, and McAleer et al. (1992) showed increased anti-tumor effects of several bioreductive drugs with hypobaric hypoxia, suggesting that blood flow was not significantly reduced.

Increased ${ }^{3} \mathrm{H}-\mathrm{MISO}$ retention with hypobaric hypoxia has been previously demonstrated in rat incisor pulps by means of a liquid scintillation technique (Baumgardner et al., 1994). This technique surveys the entire pulp organ and, as such, cannot localize sites where increased hypoxic ${ }^{3} \mathrm{H}$-MISO retention occurs. The aims of this investigation were to determine: (1) normoxic ${ }^{3} \mathrm{H}-\mathrm{MISO}$ retention rates in the dental pulp and periapex of rats, (2) whether increased ${ }^{3} \mathrm{H}-\mathrm{MISO}$ retention with hypobaric-hypoxia is detectable, and if so, (3) the specific sites where hypoxic ${ }^{3} \mathrm{H}-\mathrm{MISO}$ retention occurs.

\section{Materials and methods}

\section{Animals}

Thirty adult male Sprague-Dawley rats (average weight $=230$ grams) were divided into experimental $(\mathrm{N}=18)$ and control $(\mathrm{N}$ $=12$ ) groups. The guidelines for the ethical use of animals at the University of Iowa were followed throughout this study.

\section{Drug administration protocol}

MISO (Hoffmann-LaRoche, Nutley, NJ) was labeled with tritium $\left({ }^{3} \mathrm{H}\right)$ according to the procedure of Born and Smith (1983). All experimental animals were injected I.P. with $75 \mathrm{mg}$ ${ }^{3} \mathrm{H}-\mathrm{MISO}$ (specific activity, $4.67 \mathrm{MBq} / \mathrm{mg}$ ) per $\mathrm{kg}$ body weight. In the control group, 8 of the 12 animals were injected with 75 $\mathrm{mg} / \mathrm{kg}$ of unlabeled MISO, while the other 4 were injected with saline. All animals were maintained for $24 \mathrm{hr}$ after drug or sham treatment to allow sufficient time for clearance of unbound circulating MISO (Chin and Rauth, 1981).

\section{Hypobaric hypoxia induction}

Both experimental and control animals were divided between the normoxic and hypoxic groups. Animals in the normoxic group were maintained under normal atmospheric conditions, while animals in the hypoxic group were placed in a hypobaric chamber at $0.5 \mathrm{~atm}$. A vacuum pump attached to one end of the chamber reduced the air pressure to $0.5 \mathrm{~atm}$, while a valve at the opposite end allowed for constant fresh air inflow.

\section{Animal death and tissue-processing protocols}

After $24 \mathrm{hr}$, all animals were anesthetized with a mixture of Ketamine $\mathrm{HCl}$ (Parke-Davis, Morris Plains, NJ) plus 20\% xylazine I.P. (Mobay Corporation, Shawnee, KS) and perfused through the left ventricle with $10 \%$ normal buffered formalin.

The maxillary incisors and maxillary and mandibular molars with surrounding periradicular bone were dissected en bloc and submerged in $10 \%$ normal buffered formalin for a minimum of $48 \mathrm{hr}$. Samples were decalcified by means of $10 \%$ ethylenediaminetetraacetic acid (EDTA) with hydrochloric acid (SP-Decalcifying Solution ${ }^{\mathrm{T}}$, Baxter Scientific Products, McGaw Park, IL). Decalcification was monitored radiographically. After demineralization (about $30 \mathrm{hr}$ ), samples were rinsed under running tap water for $2 \mathrm{hr}$, then processed through graded alcohols to paraffin. We prepared subbed slides by dipping clean slides into a solution of $5.0 \mathrm{gm}$ gelatin and $0.5 \mathrm{gm}$ chromium potassium sulfate per $1000 \mathrm{cc}$ distilled water and then air-drying them. Serial sections $4 \mu \mathrm{m}$ thick were cut from all blocks and placed on the subbed slides. The molar and incisor blocks were sectioned through the entire extent of the pulp along a mesialdistal plane parallel to the long axis of the tooth.

Samples were de-waxed and dipped in Kodak ${ }^{(1)}$ NTB2 autoradiographic nuclear track emulsion under proper darkroom conditions. The slides were stored in light-tight boxes under refrigeration at approximately $4^{\circ} \mathrm{C}$. At appropriate intervals, slides were removed from storage, developed, stained with hematoxylin and eosin, and coverslipped.

At minimum, every tenth sequential serial section was examined by light microscopy, scanned for proper histologic sectioning, and then checked for autoradiographic grain density per unit area with the aid of an ocular grid square. Selected samples were digitized on the Videk Megaplus image acquisition system (Perceptics Corp., Knoxville, TN) and evaluated by computer (Apple ${ }^{\circledR}$ Macintosh IIci, Apple Computer, Inc.). The output of the digital camera was amplified and digitized into a $1024 \times 1024$ pixel array, such that each pixel had a gray level range of from 0 (white) to 255 (black). For each section that was digitized, an empty field image was also digitized and subtracted from the section image to reduce greylevel variation within the image due to location in the field (Fischer and Bond, 1972).

\section{Statistical estimation of bound ${ }^{3} \mathrm{H}-\mathrm{MISO}$}

We estimated bound ${ }^{3} \mathrm{H}$-MISO by counting grains overlying a minimum of $200 \mu \mathrm{m}^{2}$ of tissue. Autoradiographic development times were chosen based upon the period of exposure which produced maximum grain number with minimum grain overlap (fewer than 120 grains per $22.5 \mathrm{\mu m}^{2}$ grid square over the area of greatest activity). Comparisons of normoxic and hypoxic samples were performed under identical development and processing procedures.

Estimates of the minimum number of counts needed for statistical accuracy were patterned after England and Rogers (1970) and England and Miller (1970). In area A, where $\lambda$ is the 
theoretical grain density, the average number of grains is Ave $(n)=\lambda(A)$. If $\lambda_{B}$ is an estimation of background grain density and $\lambda_{S+B}$ an estimate of sample activity including background, then the estimate $\lambda_{S}$ of true sample activity has an average, variance, and coefficient of variation as follows:

$$
\begin{aligned}
& \operatorname{Ave}\left(\lambda_{S}\right)=\operatorname{Ave}\left(\lambda_{S+B}\right)-\operatorname{Ave}\left(\lambda_{B}\right) \\
& \operatorname{Var}\left(\lambda_{S}\right)=\operatorname{Var}\left(\lambda_{S+B}\right)+\operatorname{Var}\left(\lambda_{B}\right) \\
& \operatorname{CV}\left(\lambda_{S}\right)=\sqrt{\frac{1}{\lambda_{S}^{2}}\left(\frac{\lambda_{S+B}}{A_{B+S}}+\frac{\lambda_{B}}{A_{B}}\right)}
\end{aligned}
$$

The acceptable coefficient of variation for the grain count was set at $0.10 . \mathrm{N}$, the number of grains that must be counted to maintain this coefficient of variation, was derived from:

$$
N=\frac{1}{(C V)^{2}}\left(\frac{\rho^{2}+2 \rho+2}{\rho^{2}}\right)
$$

where $\rho$ was estimated by the ratio $\lambda_{S} / \lambda_{B}$ (England and Miller, $1970)$. Typically, the number of grains that needed to be counted for statistical validity approximated 500 grains per sample.

Background counts per unit area were obtained from the emulsion layer just coronal to the molar or incisal edge, where no underlying tissue was present.

We estimated true grain counts per unit area $\left(\lambda_{S}\right)$ by subtracting existing background counts $\left(\lambda_{B}\right)$ from the total sample activity, which is in reality $\lambda_{\mathrm{S}+\mathrm{B}}$ (Eq. 1 ). Therefore, the standard deviation of $\lambda_{S}$ was calculated with propagation of error by taking the square root of the variance of the total sample activity plus the variance of the background counts (Eq. 2). Sample distributions were analyzed by Bartlett's test for homogeneity of variance. Since all populations were found to be normally distributed, all two-group comparisons wre made with the $t$ test, and all multiple group comparisons were made with ANOVA, with $p<0.05$ accepted as significant (England and Miller, 1970). Where appropriate, post hoc ANOVA results had further pairwise analysis by Scheffës F test (Scheffé, 1953).

Table 1. Grain counts in coronal molar pulp

\begin{tabular}{lcc} 
& \multicolumn{2}{c}{ Mean $^{\mathrm{a}} \pm \mathrm{SD}$} \\
\cline { 2 - 3 } Group & Normoxic & Hypoxic \\
\hline Experimental ( $\left.{ }^{3} \mathrm{H}-\mathrm{MISO}\right)$ & $82 \pm 16^{\mathrm{b}}(\mathrm{n}=9)$ & $345 \pm 51 \mathrm{~b}, \mathrm{c}(\mathrm{n}=9)$ \\
Unlabeled MISO & $2 \pm 8(\mathrm{n}=4)$ & $2 \pm 5(\mathrm{n}=4)$ \\
Saline controls & $0 \pm 7(\mathrm{n}=2)$ & $0 \pm 8(\mathrm{n}=2)$ \\
\hline
\end{tabular}

Sample mean count per $100 \mu^{2}$ corrected for background [i.e., Sample Ave $\left.\left(\lambda_{S}\right)\right]$

b Samples that were significantly different from saline control animals (ANOVA, Scheffé post hoc test at $\mathrm{p}<0.05$ ).

Samples that were significantly different from normoxic animals at $p<0.05$.

There were no significant differences between saline and unlabeled MISO control groups.

\section{Results}

Both normoxic and hypoxic animals retained ${ }^{3} \mathrm{H}-\mathrm{MISO}$, as demonstrated by the significant increase in autoradiographic grain counts in these animals over the saline and unlabeled MISO controls (Table 1). In addition, hypoxic animals had a significant increase in the amount of ${ }^{3} \mathrm{H}$-MISO retained when compared with their normoxic counterparts. The degree of ${ }^{3} \mathrm{H}-\mathrm{MISO}$ retention in the normoxic animals was stable and consistent in all areas observed in the rat molar and incisor, with the exception of the ameloblasts and odontoblasts in the continually erupting incisor. The normoxic ${ }^{3} \mathrm{H}-\mathrm{MISO}$ retention rate varied in these two cell types at different maturation stages.

\section{Incisor ameloblasts}

In the enamel organ, the region of greatest autoradiographic grain density was the ameloblast layer. The amount of ${ }^{3} \mathrm{H}$ MISO retained significantly increased as the cells matured from the apex to the incisal edge (Figs. 1, 2). Although increased retention with cell maturation was seen in both the normoxic- and hypoxic-induced samples, hypoxia significantly increased the amount of ${ }^{3} \mathrm{H}$-MISO retained at each stage of development when compared with similar morphologic sites in normoxic animals (compare Fig. 1 with Fig. 2 and Table 2). As can be noted from Figs. 1 and 2, increased ${ }^{3} \mathrm{H}$-MISO retention occurred in the stratum intermedium and papillary layers of the enamel organ, although to a lesser extent than in the ameloblast layer. Because it was difficult to distinguish these two layers distinctly in 4- $\mu \mathrm{m}$ autoradiographs throughout the entire length of the incisor (Warshawsky and Smith, 1974), we quantified only the ameloblast layer (Table 2).

\section{Incisor odontoblasts}

In contrast to ameloblasts, odontoblasts retained more ${ }^{3} \mathrm{H}-$ MISO in the immature cell type. Pindborg and Weinmann (1959) divide the rat incisor into 5 morphologic sectors from the

\begin{tabular}{|c|c|c|}
\hline \multirow[b]{2}{*}{ Region } & \multicolumn{2}{|c|}{$\begin{array}{c}\text { Mean }^{\mathrm{a}} \pm \mathrm{SD} \\
(\mathrm{n}=9 \text { for each group })\end{array}$} \\
\hline & Normoxic & Hypoxic \\
\hline Apical third & $38 \pm 5^{c}$ & $187 \pm 31^{b, d}$ \\
\hline Middle Third & $60 \pm 8$ & $334 \pm 42^{b, d}$ \\
\hline Incisal Third & $124 \pm 22^{c}$ & $521 \pm 61^{b, d}$ \\
\hline
\end{tabular}
apex to the incisal edge. The amount of ${ }^{3} \mathrm{H}$-MTSO retained in the odontoblast layer was significantly higher in sectors 1 and

Table 2. Grain counts in incisor ameloblasts

a Sample mean count per $100 \mu \mathrm{m}^{2}$ corrected for background [i.e., Sample Ave $\left.\left(\lambda_{S}\right)\right]$.

b Hypoxic samples that were significantly different from similar morphologic normoxic samples (ANOVA, Scheffés test at $p<0.05$ ).

c Normoxic regions that were significantly different from each other at $p<0.05$.

d Hypoxic regions that were significantly different from each other at $\mathrm{p}<0.05$. 

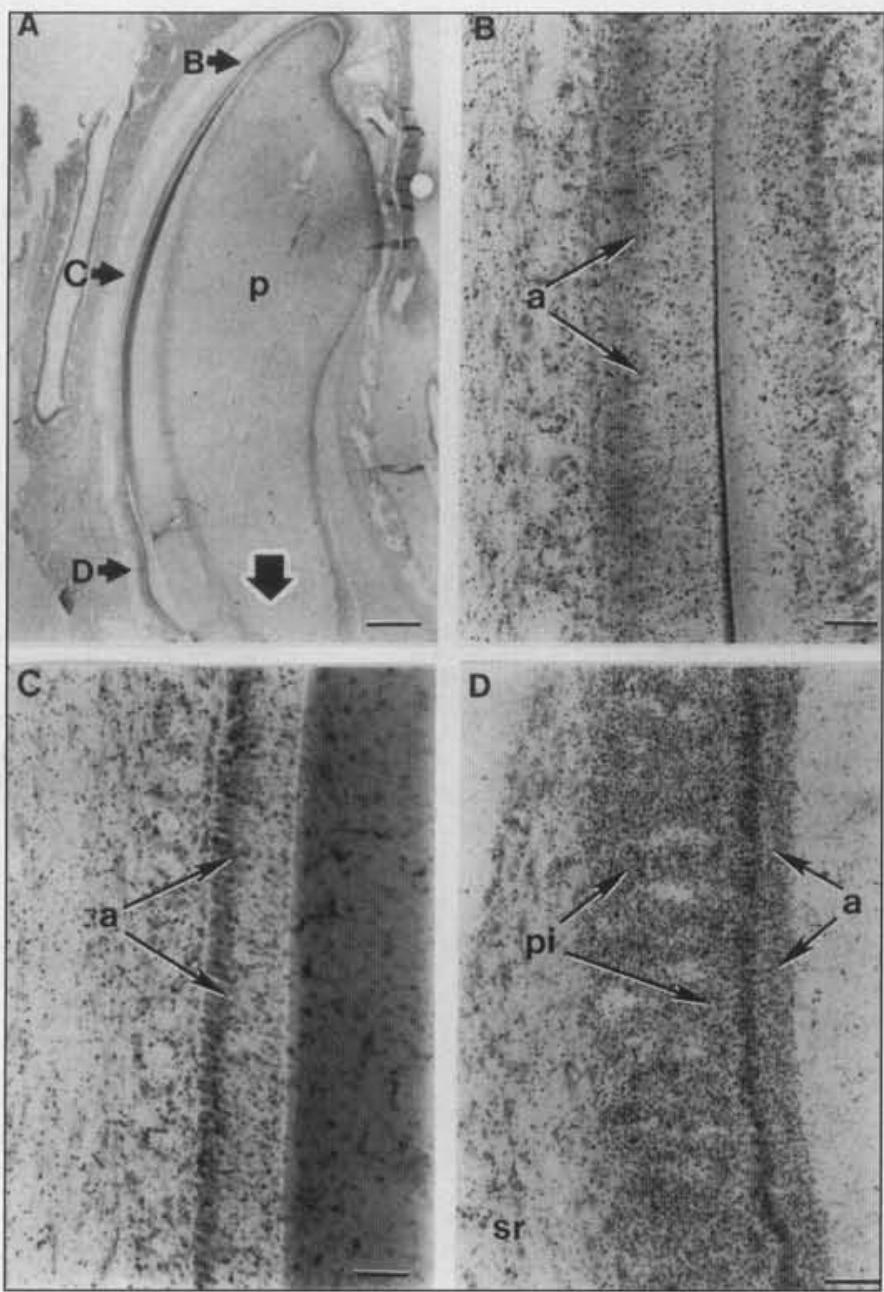

Figure 1. Normoxic rat incisor. (A) Low-power view of the incisor (original mag., 26x). Apical, middle, and incisal thirds of the ameloblast layer are labeled with lettered arrows, enlarged, and shown in B, C, and D, respectively. Large arrow points to direction of eruption, i.e., toward incisal edge. (B) Enlarged view of ameloblasts (a) in the apical third. (C) Enlarged view of ameloblasts (a) in the middle third. (D) Enlarged view of ameloblasts (a) in the inicsal third. Note increased ${ }^{3} \mathrm{H}$-MISO retention from apical to incisal third (see Table 2) and compare with similar areas in the hypoxic incisor in Fig. 2. There is also increased ${ }^{3} \mathrm{H}-\mathrm{MISO}$ in the papillary and stratum intermedium layers (pi) compared with the stellate reticulum $(\mathrm{sr}) \cdot \mathrm{p}=$ pulp; $\mathrm{a}=$ ameloblasts; $\mathrm{pi}=$ papillary and stratum intermedium layers; $\mathrm{sr}=$ stellate reticulum. Scale bar is 380 $\mu \mathrm{m}$ for $\mathrm{A}$ and $20 \mu \mathrm{m}$ for B, C, and D.

2 , which extend from the apex to the point where enamel formation starts, than in the remaining 3 , more incisal, sectors (Fig. 3). Past sector 2, the amount of ${ }^{3} \mathrm{H}$-MISO retained in odontoblasts abruptly decreased and stayed constant at this lower level throughout the remainder of the incisor. Odontoblasts from hypoxic animals retained significantly more ${ }^{3} \mathrm{H}-\mathrm{MISO}$ at each stage of development than odontoblasts from comparable morphologic sites in normoxic animals (Table 3 ).

\section{Molar pulp and periapex}

When morphologically equivalent sites were compared, hypoxic animals always had statistically significant increased
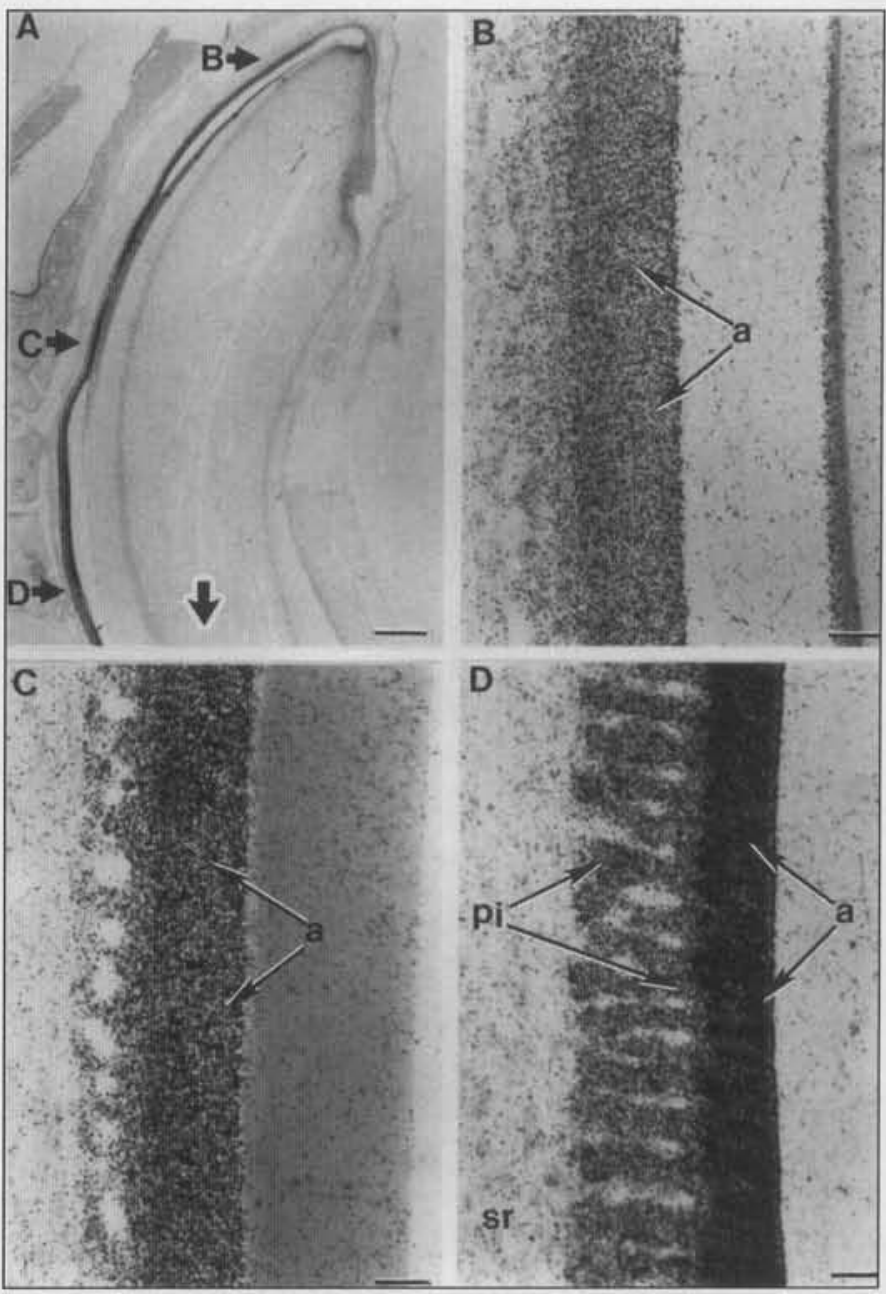

Figure 2. Hypoxic rat incisor. (A) Low-power view of the incisor (original mag., 26x). Apical, middle, and incisal thirds of the ameloblast layer are labeled with lettered arrows, enlarged, and shown in B, C, and D, respectively. Large arrow points to direction of eruption, i.e., toward incisal edge. (B) Enlarged view of ameloblasts (a) in the apical third. (C) Enlarged view of ameloblasts (a) in the middle third. (D) Enlarged view of ameloblasts (a) in the incisal third. Note increased ${ }^{3} \mathrm{H}$-MISO retention from apical to incisal third. Compare with similar areas in the normoxic incisor in Fig. 1. Hypoxia increased the amount of ${ }^{3} \mathrm{H}$-MISO retained when compared with corresponding areas in normoxic incisor (see Table 2 ). $\mathrm{a}=$ ameloblasts; $\mathrm{pi}$ = papillary and stratum intermedium layers; $s r=$ stellate reticulum. Scale bar is $380 \mu \mathrm{m}$ for $\mathrm{A}$ and $20 \mu \mathrm{m}$ for B, C, and D.

${ }^{3} \mathrm{H}$-MISO retention over normoxic animals. In addition, specific hypoxic sites retained more ${ }^{3} \mathrm{H}-\mathrm{MISO}$ than other hypoxic areas within the same animal. Specifically, regions where intense hypoxic cell labeling occurred were: (1) molar pulp horn odontoblasts (Fig. 4), (2) osteocytes in the periradicular bone (Fig. 5), and (3) cementocytes (Fig. 6) and the periodontal ligament directly surrounding them (Fig. 7). Osteocytes and cementocytes displayed intense ${ }^{3} \mathrm{H}-\mathrm{MISO}$ retention in all hypoxic samples examined. In contrast, the pulp horn odontoblasts and periodontal ligament displayed intense hypoxic ${ }^{3} \mathrm{H}$-MISO retention only sporadically.

${ }^{3} \mathrm{H}$-MISO retention was uniformly distributed throughout the central and peripheral regions of molar 


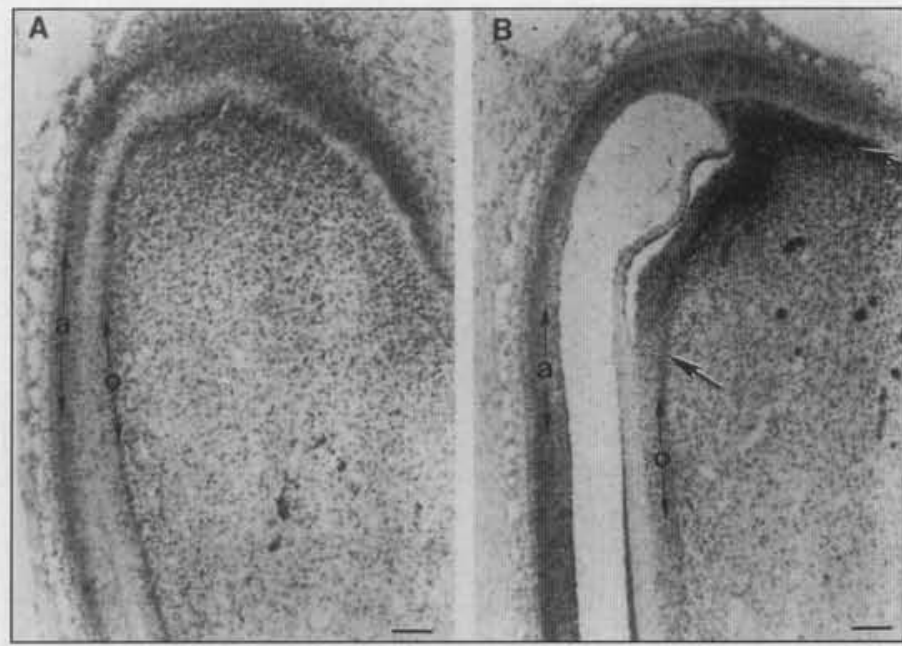

Figure 3. Incisor odontoblasts. (A) Autoradiograph of apical area from normoxic animal. (B) Autoradiograph of apical area from hypoxic animal. Note intense ${ }^{3} \mathrm{H}$-MISO retention in immature odontoblasts (large arrows). $\mathrm{a}=$ ameloblasts; $\mathrm{o}=$ odontoblasts. Scale bar is $30 \mu \mathrm{m}$ for both $\mathrm{A}$ and $\mathrm{B}$.

pulp. The only exception occurred in hypoxic pulps when occasional clusters of pulp horn odontoblasts had intense ${ }^{3} \mathrm{H}$-MISO labeling (Fig. 4). In normoxic molar pulp, there was no statistical difference in the degree of ${ }^{3} \mathrm{H}-\mathrm{MISO}$ retention between odontoblasts and the cells of the central pulp (Table 4). This was also true for hypoxic molar pulp when the intensely labeled hypoxic pulp horn odontoblasts were excluded. There was always a statistically significant increase in ${ }^{3} \mathrm{H}$-MISO retention from normoxic to hypoxic pulps, regardless of the region examined (Table 4).

Neither cell necrosis nor inflammation was ever observed histologically in any of the samples examined, which supports the conclusions of Cobb et al. (1989a) that MISO at a dose of $75 \mathrm{mg} / \mathrm{kg}$ does not produce acute cytotoxic effects.

\section{Discussion}

MISO was originally thought to bind in significant amounts only in hypoxic tissues, since, in normoxic tissues, oxygen would prevent formation of the reactive species (Franko, 1986).

Table 3. Grain counts in incisor odontoblasts

\begin{tabular}{|c|c|c|}
\hline \multirow[b]{2}{*}{ Region } & \multicolumn{2}{|c|}{$\begin{array}{c}\text { Mean }^{\mathrm{a}} \pm \mathrm{SD} \\
(\mathrm{n}=9 \text { for each group) }\end{array}$} \\
\hline & Normoxic & Hypoxic \\
\hline Pre-odontoblasts (from Sector 1) & $115 \pm 18^{c}$ & $518 \pm 63^{b, d}$ \\
\hline Odontoblasts (from Sector 3) & $75 \pm 10^{c}$ & $337 \pm 41^{\mathrm{b}, \mathrm{d}}$ \\
\hline
\end{tabular}

a Sample mean count per $100 \mu \mathrm{m}^{2}$ corrected for background [i.e., Sample Ave $\left.\left(\lambda_{\mathrm{s}}\right)\right]$.

b Hypoxic samples that were significantly different from similar morphologic normoxic sample $(t$ test at $\mathrm{p}<0.05$ ).

Normoxic regions that were significantly different from each other at $\mathrm{p}<0.05$.

d Hypoxic regions that were significantly different from each other at $\mathrm{p}<0.05$.

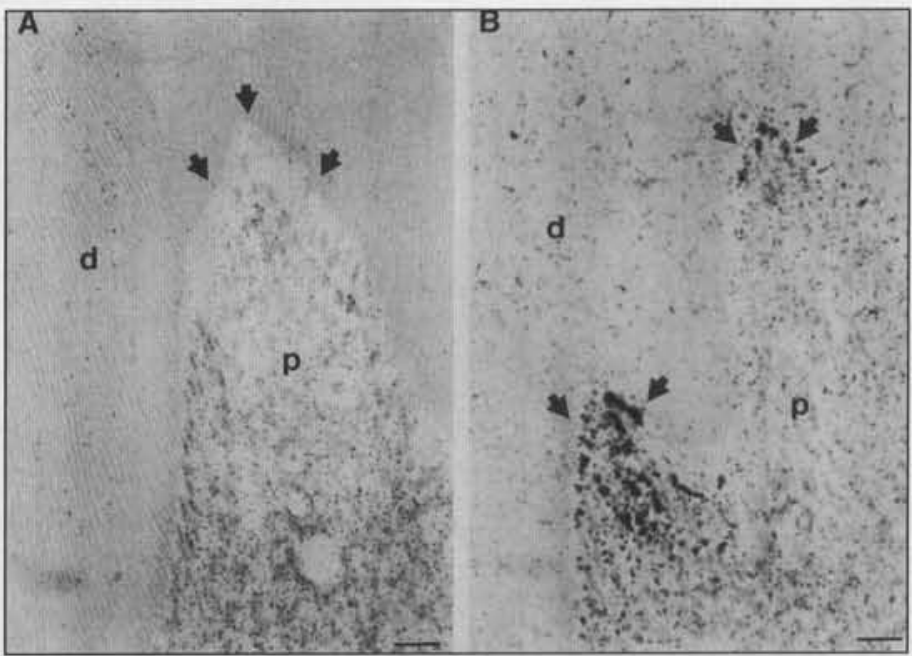

Figure 4. ${ }^{3} \mathrm{H}$-MISO retention in molar pulp horn. (A) Normoxic molar pulp horn (arrows). (B) Hypoxic molar pulp horn. Note intense labeling compared with normoxic horn (arrows). $\mathrm{d}=$ dentin, $\mathrm{p}=$ pulp. Scale bar is $20 \mu \mathrm{m}$ for both A and B.

Cobb et al. $(1989 \mathrm{a}, \mathrm{b})$ conducted an autoradiographic survey of normoxic tissues in the mouse and found that a number of tissues accumulated ${ }^{3} \mathrm{H}-\mathrm{MISO}$ intensely, even under putative normoxic conditions. The study by Cobb et al. (1989a,b) surveyed normoxic retention only and found that (unspecified) cells of the enamel organ retained ${ }^{3} \mathrm{H}$-MISO at a significantly greater rate than stroma. Data from the present study found that normoxic tissue retains ${ }^{3} \mathrm{H}-\mathrm{MISO}$ and that the rate of retention varies in some cells. However, the normoxic retention rate in all regions was always significantly lower than that found in similar regions from hypoxic animals.

In general, the bioreduction of MISO to the hydroxylamine required for cellular binding is dependent upon both the number of reducing equivalents available in the tissue (oxygen-independent binding) and the relative oxygen tension in the cell (oxygen-dependent binding) (Parliament et al., 1992). The experimentally induced hypobaric hypoxia created an environment that facilitated increased MISO binding to the dental pulp and surrounding tissues. Hypoxia induction does not appear to affect

Table 4. Grain counts in molar pulp by cell type.

\begin{tabular}{lcc}
\hline \multirow{2}{*}{ Region } & \multicolumn{2}{c}{$\begin{array}{c}\text { Mean }{ }^{\mathrm{a}} \pm \text { SD } \\
(\mathrm{n}=9 \text { for each group) }\end{array}$} \\
\cline { 2 - 3 } & Normoxic & Hypoxic \\
\hline Odontoblasts & $88 \pm 15$ & $352 \pm 58^{\mathrm{b}}$ \\
Central pulp & $77 \pm 12$ & $341 \pm 51^{\mathrm{b}}$ \\
\hline
\end{tabular}

a Sample mean count per $100 \mu \mathrm{m}^{2}$ corrected for background [i.e., Sample Ave $\left.\left(\lambda_{S}\right)\right]$.

b Hypoxic samples that were significantly different from similar morphologic normoxic samples $(t$ test at $\mathrm{p}<0.05$ ).

There was no significant difference between odontoblasts and coronal central pulp within the same animal in either the normoxic or hypoxic samples; intensely labeled hypoxic pulp horn odontoblasts were excluded. 


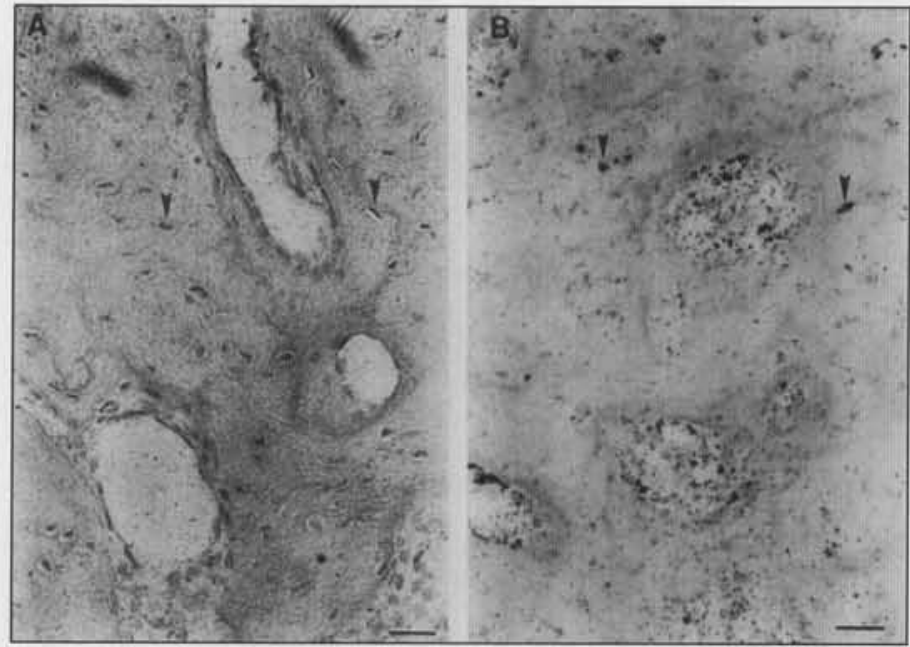

Figure 5. ${ }^{3} \mathrm{H}$-MISO retention in periradicular osteocytes. Arrows indicate osteocytes in a normoxic animal (A) as compared with a hypoxic animal (B). Note increased ${ }^{3} \mathrm{H}$-MISO retention with induced hypoxia. Scale bar is $20 \mu \mathrm{m}$ for both A and B.

differences in oxygen-independent MISO retention among tissues due to their different reducing capacities. The observations that hypoxia increased ${ }^{3} \mathrm{H}$-MISO retention even when the normoxic, oxygen-independent retention rate varied (as in maturing ameloblasts and odontoblasts in the incisor) demonstrate that hypobaric hypoxia mediated oxygen-dependent binding of ${ }^{3} \mathrm{H}-\mathrm{MISO}$. The normoxic ${ }^{3} \mathrm{H}-$ MISO retention level should be considered a baseline value that is cell-type-specific. Differences in baseline normoxic values among tissues may account for the variations in autoradiographic grain densities noted by Cobb et al. (1989a) without invalidating MISO's use as a hypoxic cell marker.

The abrupt decrease in ${ }^{3} \mathrm{H}$-MISO retention from preodontoblasts to odontoblasts may be related to their differentiation stage. Odontoblasts have mesodermal origins (Reith, 1968). Mesenchyme, per se, characteristically demonstrates low ${ }^{3} \mathrm{H}$-MISO retention when compared with other tissues (Cobb et al., 1989a; McManus et al., 1989; Baumgardner et al., 1994). The differentiation of odontoblasts may thus proceed along a path favoring lowered ${ }^{3} \mathrm{H}$-MISO retention.

Factors other than differentiation might be involved with increased ${ }^{3} \mathrm{H}$-MISO retention in maturing ameloblasts. Ameloblasts in the rat incisor: (1) undergo a phenotypic change to that of sulcular epithelium and (2) become atrophic.

Once enamel formation is complete, ameloblasts and outer layers of the enamel organ atrophy, fuse together into reducedenamel epithelium, and eventually unite with the sulcular epithelium (Pannese, 1962). Epithelium has been shown (Cobb et al., 1989a) to have a high ${ }^{3} \mathrm{H}-\mathrm{MISO}$ retention level; we have noted the same phenomenon (unpublished data). Possibly, increased ${ }^{3} \mathrm{H}$-MISO retention in maturing ameloblasts is related more to a change in cell function than to stage of differentiation. In this regard, ameloblasts either undergoing atrophy or converting to sulcular epithelium provide conditions which may encourage increased ${ }^{3} \mathrm{H}-\mathrm{MISO}$ retention.

Oxygen tension in normoxic, developing bone has a

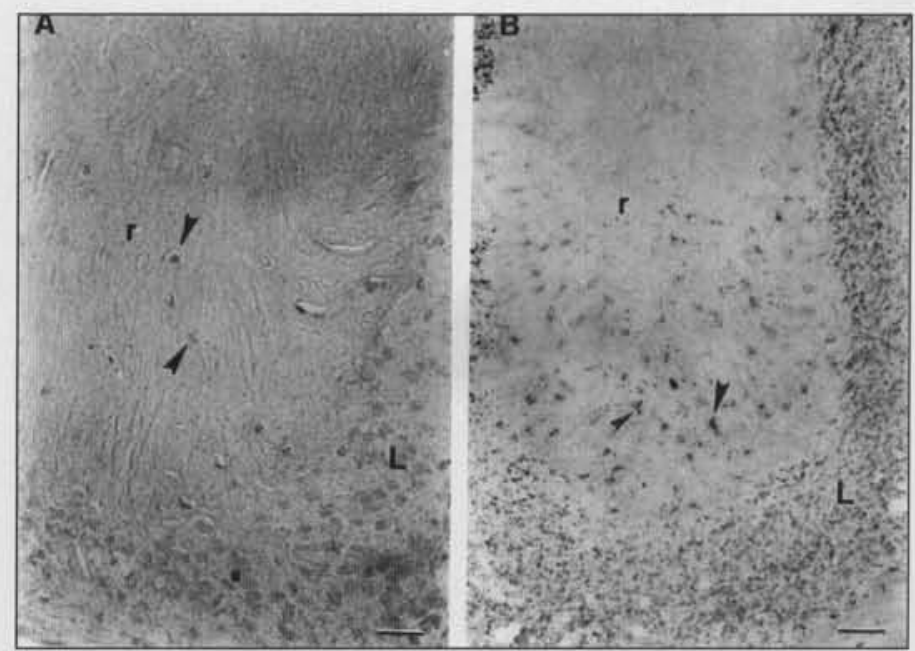

Figure 6. Cellular cementum. Arrows indicate cementocytes in a normoxic animal (A) as compared with a hypoxic animal (B). Note increased ${ }^{3} \mathrm{H}$-MISO labeling in hypoxic cementocytes and periodontal ligament. $\mathrm{r}=$ root; $\mathrm{L}=$ periodontal ligament. Scale bar is $20 \mu \mathrm{m}$ for both $\mathrm{A}$ and $\mathrm{B}$.

strong correlation with functional needs (Brighton and Heppenstall, 1971). At the age of the animals in the present study, the periradicular bone and cellular cementum were already fully developed (Paynter and Hunt, 1964). Minor variations within samples from the molar periapex were seen primarily in hypoxic bone and cementum, with ${ }^{3} \mathrm{H}$ MISO retention appearing to be most intense in cells farthest from the arterial blood supply. Based on these observations, increased ${ }^{3} \mathrm{H}$-MISO retention in the periapex appeared related more to oxygen diffusion than to pre-existing oxygen tension differences based on cell function.

In the molar region of hypoxic animals, ${ }^{3} \mathrm{H}$-MISO retention was most intense in cementocytes, osteocytes, periodontal ligament, and pulp horn odontoblasts. While cementocytes and osteocytes showed intense ${ }^{3} \mathrm{H}$-MISO retention in all hypoxic samples, periodontal ligament and pulp horn odontoblasts were more inconsistent. These findings may be related to oxygen diffusion. Cementocytes and osteocytes are both contained within lacunae and derive oxygen and nutrients by diffusion. Periodontal ligament, being closer to the blood supply, is occasionally able to maintain a higher oxygen tension under hypoxic conditions. However, cementocytes and osteocytes, being farthest from the blood supply, were never able to maintain a high oxygen tension in the hypoxic animals.

When molar odontoblasts retained ${ }^{3} \mathrm{H}-\mathrm{MISO}$ intensely, it was in hypoxic animals and only in the pulp horn area. However, as was the case with the periodontal ligament, not all hypoxic pulp horn odontoblasts retained ${ }^{3} \mathrm{H}-\mathrm{MISO}$ intensely. This inconsistency may lie with their unique and elaborate capillary network. The capillaries range from 4 to 8 $\mu \mathrm{m}$ and are located just medial to the cells (Takahashi et al., 1982). The pattern of intense ${ }^{3} \mathrm{H}$-MISO retention in pulp horn odontoblasts, when it occurred, followed the distribution of the subodontoblastic capillary plexus (Fig. 4). If this premise is correct, ${ }^{3} \mathrm{H}$-MISO retention could have occurred as a result of temporary closure of the capillary 


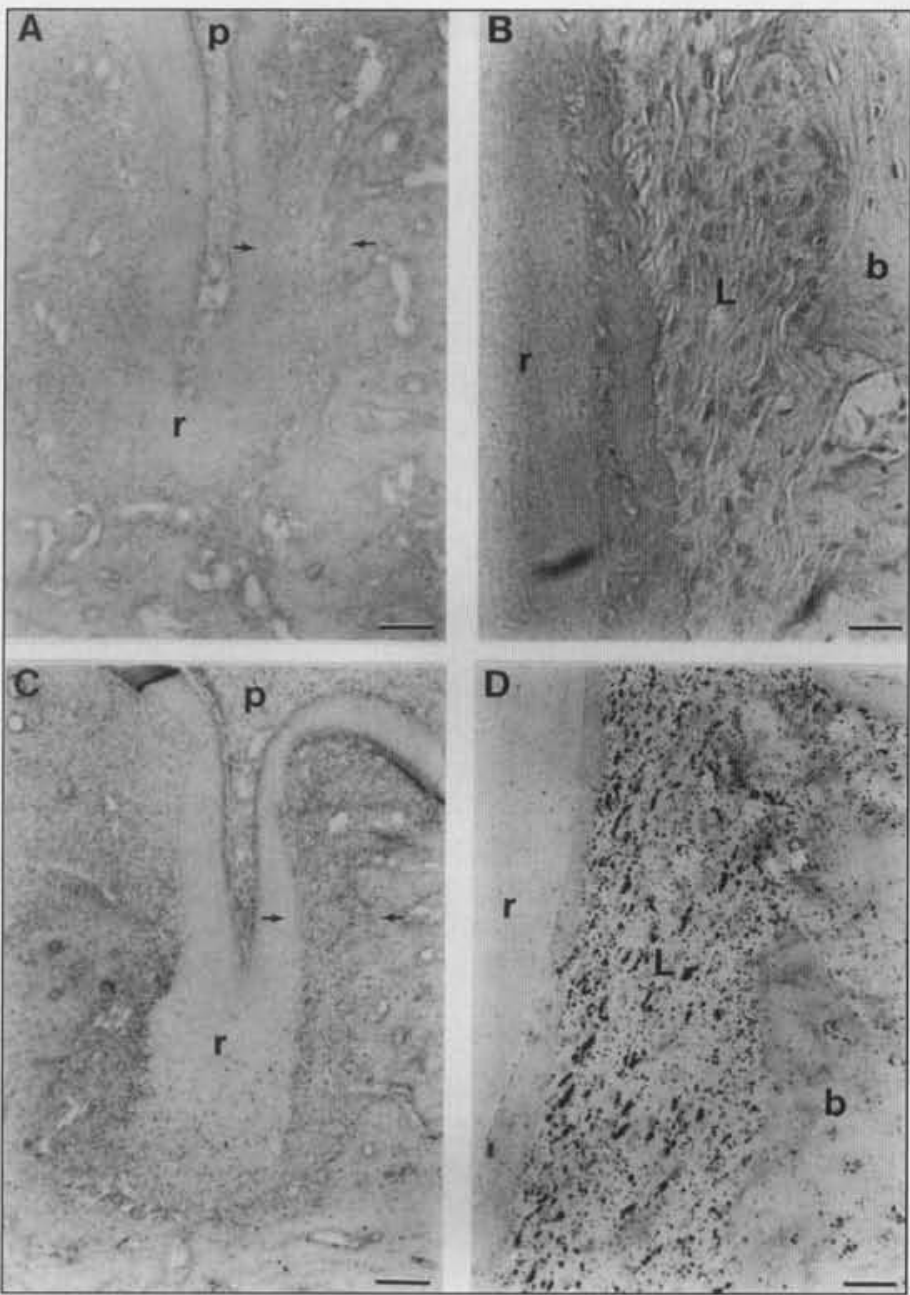

Figure 7. Molar root and periodontal ligament. (A) Molar root and surrounding periodontium from a normoxic animal. Area between arrows enlarged and shown in B. (B) Normoxic periodontium. (C) Similar area as in A but from a hypoxic animal. Area between arrows enlarged in D. (D) Hypoxic periodontium. Note intense ${ }^{3} \mathrm{H}$ MISO retention as compared with B. $\mathrm{p}=$ pulp; $\mathrm{r}=$ root; $\mathrm{L}=$ periodontal ligament; $\mathrm{b}=$ bone. Scale bar is $68 \mu \mathrm{m}$ for $\mathrm{A}$ and $\mathrm{C}$ and $20 \mu \mathrm{m}$ for $\mathrm{B}$ and $\mathrm{D}$.

bed, presumably from hypobaric pressure changes.

Brown (1979) has defined two classes of hypoxic cells, acute and chronic. Acutely hypoxic cells exist in tumors because of temporary closure of blood vessels (Brown, 1979) and are scattered randomly throughout the tumor mass (Franko, 1986). Chronically hypoxic cells, however, are localized to areas some distance from blood vessels. These chronically hypoxic cells occurred in tumors as a result of rapid cell growth beyond the ability of blood vessels to keep pace (Tannock, 1968).

Acutely and chronically hypoxic cells have been described for tumor tissues only. By analogy to the present study with the hypobaric-hypoxic system, osteocytes and cementocytes might be considered chronically hypoxic due to their positions distant from nearby vasculature. Minor disturbances in the oxygen supply likely subject these tissues to an immediate and intense hypoxic incident. Pulp horn odontoblasts and periodontal ligament, however, would be acutely hypoxic, labeling only randomly when physiologic conditions of brief vasospasm or constriction coincided with optimum ${ }^{3} \mathrm{H}-\mathrm{MISO}$ availability.

In any investigation of this type, once baseline normoxic ${ }^{3} \mathrm{H}$-MISO retention values of a tissue are established, then comparisons with a hypoxic condition can be made. Using hypobaric hypoxia-inducing techniques similar to those used in this study, MacManus et al. (1989) reported a range of 1.8 times more ${ }^{3} \mathrm{H}$-MISO retained in a hypoxic heart to 2.9 times greater retention in a hypoxic spleen. In dental pulp, hypoxia caused an increased ${ }^{3} \mathrm{H}$-MISO retention of approximately 1.6 times, when a liquid scintillation counting technique was used (Baumgardner et al., 1994). The variation in increased hypoxic retention among tissues could be due to saturation of that tissue's MISO-reducing capacity. However, differences may result from effective regional blood flow that a particular tissue is able to secure for itself in times of oxygen deprivation.

Effective blood flow is defined as that level necessary to maintain cells in the normoxic state (Baumgardner et al., 1994). Studies on blood flow typically cannot correlate changes in flow with effects on cellular oxygen perfusion. In this regard, ${ }^{3} \mathrm{H}$-MISO appears useful for the examination of dynamic changes in cellular oxygen perfusion under hypoxic conditions. With the techniques developed in this paper, it may now be possible to examine conditions which create change in blood flow (cavity preparation, inflammation, trauma, etc.) and then correlate the effects of these changes on the effective blood flow to that region.

\section{Acknowledgments}

This research was supported by NIH/NIDR Grant \#K16DE00175 (KRB).

\section{References}

Baumgardner KR, Osborne JW, Walton RE, Born JL (1994). Characterization of induced pulpal hypoxia using ${ }^{3} \mathrm{H}$ misonidazole. J Endodont 20:585-588.

Biesterfeld RC, Taintor JF, Marsh CL (1979). The significance of alterations of pulpal respiration. A review of literature. $J$ Oral Pathol 8:129-139.

Born JL, Smith BR (1983). The synthesis of tritium-labelled misonidazole. J Labelled Comp Radiopharmaceut 3:429-432.

Bremner JCM, Stratford IJ, Bowler J, Adams GE (1990). Bioreductive drugs and the selective induction of tumor hypoxia. Br J Cancer 61:717-721.

Brighton CT, Heppenstall RB (1971). Oxygen tension in zones of the epiphyseal plate, the metaphysis and diaphysis. J Bone Jt Surg 53A:719-728.

Brown JM (1979). Evidence for acutely hypoxic cells in mouse tumours, and a possible mechanism of reoxygenation. $\mathrm{Br} J$ Radiol 52:650-656.

Chaplin DJ (1986). Potentiation of RSU-1069 tumour cytotoxicity by 5-hydroxytryptamine (5-HT). Br J Cancer 54:727-731.

Chapman JD, Franko AJ, Sharplin J (1981). A marker for hypoxic cells in tumors with potential clinical applicability. Br J Cancer 43:546-550. 
Chin JB, Rauth AM (1981). The metabolism and pharmacokinetics of the hypoxic cell radiosensitizer and cytotoxic agent, misonidazole, in $\mathrm{C} 3 \mathrm{H}$ mice. Radiat Res 86:341-357.

Cobb LM, Nolan J, O'Neill P (1989a). Microscopic distribution of misonidazole in mouse tissues. Br J Cancer 59:12-16.

Cobb LM, Path FRC, Nolan J (1989b). Autoradiographic study of tritium-labeled misonidazole in the mouse. Int I Radiat Oncol Biol Phys 16:953-956.

England JM, Miller RG (1970). The statistical analysis of autoradiographs. II. Theoretical aspects including methods for optimal allocation of measurement effort. $J$ Microsc 92:167-177.

England JM, Roger AW (1970). The statistical analysis of autoradiographs. I. Grain count distributions over uniformly labelled sources. J Microsc 92:159-165.

Fischer C, Bond CP (1972). The quantimet 720D for densitometry in the life sciences. Microscope 20:203-216.

Franko AJ (1986). Misonidazole and other hypoxia markers: metabolism and applications. Int I Radiat Oncol Biol Phys 12:1195-1202.

Franko AJ, Raleigh JA, Sutherland RG, Soderlind KJ (1989). Metabolic binding of misonidazole to mouse tissues. Comparison between labels on the ring and side chain, and the production of tritiated water. Biochem Pharmac 38:665-670.

MacManus MP, Maxwell AP, Abram WP, Bridges JM (1989). The effect of hypobaric hypoxia on misonidazole binding in normal and tumour-bearing mice. Br J Cancer 59:349-352.

McAleer JJ, McKeown SR, MacManus MP, Lappin TR, Bridges JM (1992). Hypobaric hypoxia: a method for testing bioreductive drugs in vivo. Int I Radiat Oncol Biol Phys 23:551-555.

Pannese E (1962). Observations on the ultrastructure of the enamel organ. III. Internal and external enamel epithelium. J Ultrastruct Res 6:186-192.

Parliament MB, Wiebe LI, Franko AJ (1992). Nitroimidazole adducts as markers for tissue hypoxia: mechanistic studies in aerobic normal tissues and tumour cells. Br J Cancer 66:1103-1108.

Paynter KJ, Hunt AM (1964). Morphogenesis of the rat first molar. Arch Oral Biol 9:611-626.

Pindborg JJ, Weinmann JP (1959). Morphologic and functional correlations in the enamel organ of the rat incisor during amelogenesis. Acta Anat 36:367-381.

Raleigh JA, Franko AJ, Koch CJ, Born JL (1985). Binding of misonidazole to hypoxic cells in monolayer and spheroid culture: evidence that a side-chain label is bound as efficiently as a ring label. $\mathrm{Br} J$ Cancer 51:229-235.

Reith EJ (1968). Ultrastructural aspects of dentinogenesis. In: Dentin and pulp: their structure and functions. Symons NB, editor. Edinburgh: Livingstone, pp. 19-32.

Scheffé $H$ (1953). A method for judging all contrasts in the analysis of variance. Biometrika 40:87-104.

Sun J, Brown JM (1989). Enhancement of the antitumor effect of flavone acetic acid by the bioreductive cytotoxic drug SR 4233 in a murine carcinoma. Cancer Res 49:5664-5670.

Takahashi K, Kishi Y, Kim S (1982). A scanning electron microscope study of the blood vessels of dog pulp using corrosion resin casts. J Endodont 8:131-135.

Tannock IF (1968). The relation between cell proliferation and the vascular system in a transplanted mouse mammary tumour. Br I Cancer 22:258-273.

Urtasun RC, Chapman JD, Raleigh JA, Franko AJ, Koch CJ (1986). Binding of ${ }^{3} \mathrm{H}$-misonidazole to solid human tumors as a measure of tumor hypoxia. Int I Radiat Oncol Biol Phys 12:1263-1267.

Van Hassel HJ (1971). Physiology of the human dental pulp. Oral Surg Oral Med Oral Pathol 32:126-134.

Van Os-Corby DJ, Koch CI, Chapman JD (1987). Is misonidazole binding to mouse tissues a measure of cellular $\mathrm{pO}_{2}$ ? Biochem Pharmac 36:3487-3494.

Varghese AJ, Whitmore GF (1980). Binding to cellular macromolecules as a possible mechanism for the cytotoxicity of misonidazole. Cancer Res 40:2165-2169.

Varghese AJ, Gulyas S, Mohindra JK (1976). Hypoxicdependent reduction of 1-(2-nitro-1-imidazoyl)-3-methoxy2-propanol by Chinese hamster ovary cells and KHT tumor cells in vitro and in vivo. Cancer Res 36:3761-3765.

Warshawsky H, Smith CE (1974). Morphological classification of rat incisor ameloblasts. Anat $\operatorname{Rec} 179: 423-446$. 